\title{
A escrita online, os gêneros e os sistemas de atividade
}

\author{
Christiane Heemann \\ Universidade Católica de Pelotas (RS)
}

\begin{abstract}
Resumo
Olhar para os gêneros como apenas um conjunto de traços textuais que caracterizam um determinado tipo de texto não leva em conta, no uso e na construção de sentidos, o papel dos indivíduos que escrevem seus textos. Os textos adquirem vida por meio da atividade que é desenvolvida, e estudá-los sem estudar o seu contexto é separar a escrita da sua razão de ser. Levar em consideração o sistema de atividade junto com o sistema de gêneros é focalizar o que as pessoas fazem e como os textos ajudam as pessoas a fazê-lo, em vez de focalizar os textos como fins em si mesmos (Bazerman, 2005). O estudo das contradições nos sistemas de atividade (Engeström, 1987) leva a uma análise de como os sistemas de gêneros medeiam mudanças nos sistemas de atividade. Como um sistema de atividade interage com outros sistemas de forma dialética e complexa, as contradições surgem, provocando mudanças.
\end{abstract}

Palavras-chave: Gêneros; atividade; contradições; comunidades.

\begin{abstract}
Looking at genres as a group of text traits that characterize a specific kind of text does not account for the role of individuals when writing texts, in relation to the use and construction of meanings. Texts acquire life through the activity that is being developed, and studying them without studying their context is to separate writing from its reason for being. To consider activity systems together with genre systems is to focus on what people do and how their texts help them do it, instead of focusing on the texts themselves (Bazerman, 2005). The study of contradictions in activity systems (Engeström, 1987) analyzes how genre systems mediate the changes in activity systems. As an activity system interacts with other systems in a dialectical and complex way, contradictions emerge and produce changes in the systems.
\end{abstract}

Keywords: Genres; activity systems; contradictions; community

\section{INTRODUÇÃO}

A vasta publicação na área de gêneros dá-nos a falsa impressão que o assunto poderia encontrar-se esgotado. No Brasil, tal assunto vem aparecendo em pesquisa acadêmico-científicas desde o final dos anos 90. Falar do uso de diferentes gêneros tornou-se até um modismo na escola após os PCNs. É consenso trabalhar com gêneros no ensino de língua materna (Rojo, 2000; Barbosa, 2001; Ribeiro, 2001; Rojo e Cordeiro, 2004; Signorini, 
2006), pois com base nos gêneros podemos desenvolver um trabalho de produção textual fazendo uso de materiais que efetivamente circulam na sociedade (Marcuschi, 2002). Ao mantermos o foco nos gêneros textuais, podemos analisar mais do que simplesmente o funcionamento da língua; é possível compreender o próprio funcionamento de uma sociedade mediada pelas atividades discursivas, estudando e entendendo a língua como um instrumento mediador entre os sujeitos da ação social (Schneuwly, 2004). Isso porque os gêneros são "parte integrante da estrutura social e não simplesmente reflexo dessa estrutura" (Marcuschi, 2002, p.1).

Nessa perspectiva, há uma atividade que é necessariamente concebida por uma ação mediada por objetos específicos (instrumentos), "socialmente elaborados, frutos das experiências das gerações precedentes, através dos quais se transmitem e se alargam as experiências possíveis" (Schneuwly, 2004, p. 23). Segundo esse autor, os instrumentos medeiam uma atividade, dão-lhe certa forma, representam, materializam e significam uma atividade; e transformam comportamentos numa situação. Para o instrumento se tornar mediador, ou seja, transformador da atividade, precisa ser apropriado pelo sujeito, que constrói os esquemas para sua utilização. Tomando a atividade como o uso da linguagem em contextos sócio-histórico-culturais específicos com objetivos determinados, pode-se entender que, segundo Vygotsky (1978), a linguagem é um instrumento mediador que possibilita a construção de uma base de orientação para uma ação discursiva.

Temos a tendência a identificar e definir gêneros por determinadas características sinalizadoras, o que é bastante útil para que possamos interpretar e atribuir sentido aos documentos em geral. No entanto, a caracterização de gêneros como apenas um número fixo de elementos pode nos levar a ter a impressão de que estes gêneros seriam atemporais e iguais para todo mundo. Olhar para os gêneros como apenas um conjunto de traços textuais que caracterizam um determinado tipo de texto não leva em conta, no uso e na construção de sentidos, o papel dos indivíduos que escrevem seus textos (Bazerman, 2005). O gênero é uma categoria essencialmente sócio-histórica em constante mudança.

Para Bazerman (2005), desde o advento da escrita, poderosas funções da sociedade têm sido mediadas por textos escritos. O desenvolvimento da escrita "tem sido acompanhado por uma proliferação de formas escritas e situações que requerem a escrita - encaixadas dentro de sistemas de atividades cada vez mais complexos” (p. 15). A execução de tais atividades requer o aumento do número de pessoas habilitadas para lidar com essas diversas formas de escrita. Entender a escrita não é somente um problema da Linguística, mas principalmente da educação. Assim, o ensino da leitura e da escrita deve ir além de textos 
bem formados, com observação de todas as regras gramaticais, mas muitas vezes sem conteúdo algum, sem nenhuma argumentação. Neste sentido, Bazerman (2005) afirma que

\begin{abstract}
Primeiro, o escrever bem requer mais do que produção de sentenças corretas, também envolve a comunicação bem-sucedida de mensagens significantes para outros. Segundo, a escrita é um processo que leva tempo e incorpora muitas diferentes atividades. Terceiro, o ensino da escrita que ajuda os alunos a alcançarem o sucesso acadêmico precisa atender a todos os tipos de escrita que são necessários não somente para o estudo da linguagem ou da literatura, mas também para as disciplinas de história, ciência, filosofia e política. Quarto, os alunos aos terminarem os seus estudos, precisam estar aptos a produzir muitas diferentes formas de escrita. (...) os alunos precisam de habilidade e flexibilidade suficientes para se adaptar às situações variantes da escrita. (p. 16)
\end{abstract}

Cada uma dessas realizações leva o ensino e a aprendizagem da escrita para além das formas gerais de correção e para dentro da variedade de enunciados e formas da escrita. Tal abordagem entende o gênero como algo que as pessoas produzem e usam a partir de motivos e ações típicas do seu cotidiano, associados com as suas atividades. Os textos materializamse nas mais diversas formas e funcionam de modos diferentes em situações sociais do dia-adia. Isso não quer dizer que os gêneros são fruto de invenções individuais, mas formas socialmente maturadas em práticas comunicativas (Marcuschi, 2002), esta posição central também pode ser encontrada em Bakhtin (1997) que tratava os gêneros como atividades enunciativas "relativamente estáveis".

Escrever determinados textos em determinadas atividades faz com que vejamos sistemas organizacionais bem articulados dentro dos quais tipos específicos de textos circulam por caminhos previsíveis, com consequências familiares e de fácil compreensão. "Temos gêneros altamente tipificados de documentos e estruturas sociais altamente tipificadas nas quais esses documentos criam fatos sociais que afetam as ações, direitos e deveres das pessoas". (Bazerman, 2005, p. 21)

A ideia de que é impossível desvincular a linguagem da atividade humana está relacionada com a noção de gêneros discursivos. No entanto, não podemos falar de gêneros "sem pensar na esfera de atividades específicas em que eles se constituem e atuam, ai implicadas as condições de produção, de circulação e de recepção" (Brait, 2002, p.38). O estudo do gênero como ação social envolve participantes específicos em momentos e lugares específicos, é o objetivo central da corrente que aborda o "gênero como ação social" (Miller, 1994), cujo entendimento propõe olhar a escrita como a instância que visa atingir determinado propósito em determinada ação social. 
Assim, quando se considera o sistema de atividades junto com o sistema de gêneros, focaliza-se o que as pessoas fazem e como os textos ajudam a fazê-lo (Bazerman, 2005). É sob esta perspectiva que o presente trabalho foi desenvolvido.

\section{OS GÊNEROS COMO AÇÃO SOCIAL}

O estudo dos gêneros reúne análises de textos e discursos com uma visão da sociedade, tratando a linguagem em seu cotidiano nas mais diferentes formas e situações. Sob essa visão, podemos dizer que os gêneros são uma "forma de ação social” (Miller, 1994). E se gênero representa ação, envolve também situação e motivo, porque a ação humana, ainda que simbólica ou não, "só pode ser interpretada dentro de um contexto situacional e por meio de atribuição de motivos" (Miller, 1994, p.24).

$\mathrm{Na}$ abordagem de gêneros como ação social, orientada principalmente para aspectos sociais das comunidades, os gêneros podem incorporar interesses e valores de um grupo social em particular e reforçar regras sociais e relações entre escritores e leitores. Nessa perspectiva, textos podem ter efeitos sobre a vida das pessoas, podem mudar conhecimentos, crenças, atitudes e valores. Assim, para termos os significados compreendidos, é preciso entender a relação entre os participantes do evento social de que o texto faz parte. $\mathrm{Na}$ concepção de Bazerman (2006)

Gêneros não são apenas formas. Gêneros são formas de vida, modos de ser. São frames para a ação social. São ambientes para a aprendizagem. São os lugares onde o sentido é construído. Os gêneros moldam os pensamentos que formamos e as comunicações através das quais interagimos. Gêneros são os lugares familiares para onde nos dirigimos para criar ações comunicativas inteligíveis uns com os outros e são os modelos que utilizamos para explorar o não-familiar. (p.23)

Bazerman (2006) advoga que pelo uso de textos, não só organizamos nossas ações diárias, mas também damos significado a um processo interativo tipificado num sistema de atividades que encadeia significativamente as ações discursivas. Para ele, os gêneros surgem a partir de um veio histórico, cultural e interativo dentro de instituições e atividades anteriormente já existentes. Tal visão compartilha da ideia de que um gênero deve ser trabalhado com a compreensão do seu funcionamento na sociedade e na sua relação com os indivíduos situados em uma cultura e uma determinada instituição (Marcuschi, 2005). Os gêneros, para Bazerman (2006), estão ligados as nossas ações diárias; uma vez que somos seres sociais, e nesta condição agimos discursivamente na sociedade, o nosso engajamento 
pessoal na sociedade se dá por meio dos gêneros. Para aquele autor, "dominar gêneros, é agir politicamente" (Marcuschi, 2005).

Definir gêneros apenas como um conjunto de traços textuais ignora o papel dos indivíduos no uso e na construção de sentidos (Bazerman, 2005). Os gêneros emergem nos processos sociais em que as pessoas tentam compreender umas às outras suficientemente bem para coordenar atividades e compartilhar significados com vistas a seus propósitos práticos. Os textos produzidos por uma pessoa no exercício de uma determinada atividade correspondem, para Bazerman (2005), a um conjunto de gêneros. Esse conjunto equivale a todos os gêneros utilizados por um sujeito para exercer o seu papel dentro do grupo em que participa. A identificação de um conjunto de gêneros possibilita a identificação das atividades típicas de um determinado profissional no desempenho de sua atividade.

\section{A TEORIA DA ATIVIDADE}

A teoria da atividade é um suporte filosófico sócio-histórico e sociocultural através do qual é possível estudar diferentes formas das práticas humanas - as atividades - como processos de desenvolvimento. A teoria da atividade tem suas raízes na filosofia alemã do século XIX com Kant e Hegel e no materialismo dialético de Marx e Engels; mas ela foi iniciada mesmo por um grupo de psicólogos russos liderados por Vygotsky e seus colegas Leontiev e Luria por volta dos anos 20. Eles formularam um conceito totalmente novo para transcender o behaviorismo, corrente da psicologia que prevalecia na época. Para Kuutti (1996, p. 25), a teoria da atividade "é uma estrutura filosófica e interdisciplinar para estudar as diferentes formas de práticas humanas como processos de desenvolvimento, com os níveis individuais e sociais ligados ao mesmo tempo". Ao postular que a aprendizagem emerge da atividade e está ligada à performance, a teoria da atividade brinda uma maneira alternativa de olhar para o pensamento e atividade humana. Na visão de Bodker (1991), a teoria da atividade é um suporte útil para entender a totalidade do trabalho humano e da prática, que é a atividade dentro de um contexto. Dentro de uma visão bem geral de descrição, os seguidores da teoria da atividade procuram analisar o desenvolvimento da consciência dentro da atividade prática social (Daniels, 2008).

Tal teoria focaliza o relacionamento dinâmico entre a consciência e a atividade. Ao invés de ser um processo de transmissão, o conhecimento é construído baseado na intencionalidade, na história, na cultura, e na mediação das ferramentas usadas no processo. A consciência não é um conjunto de atos isolados, mas o resultado de uma prática diária. $\mathrm{O}$ 
processo consciente de dar sentido às coisas emerge da atividade ou da reflexão pessoal sobre a atividade; "a consciência está localizada na sua prática diária: você é o que você faz" (Nardi, 1996, p.7). A teoria da atividade analisa a consciência e o comportamento humano em termos de sistemas de atividade, onde as interações humanas são orientadas a um objetivo e são historicamente situadas (Russell, 1995).

Assim, a teoria da atividade propõe que a atividade - aquilo que o ser humano faz - é considerada como chave para o desenvolvimento tanto do objeto quanto do sujeito. Mudanças que ocorrem no desenvolvimento do sujeito, resultantes da sua participação em atividades, podem também causar mudanças substanciais nas próprias características do sujeito como um ser participante de uma determinada esfera social (Kaptelinin e Nardi, 2006). Dessa forma, a atividade como unidade de análise proporciona uma forma de entender sujeitos e objetos, um entendimento que não poderia ser alcançado se fosse estudado somente um ou outro separadamente.

Os componentes de qualquer atividade podem ser organizados dentro de um modelo de sistema de atividade humana (Engeström, 1987; cf. - Figura 1), que é composto por sujeitos, objeto, ferramentas, regras, comunidade e divisão do trabalho. Os sujeitos do modelo representam a natureza coletiva e individual da atividade humana por meio do uso de ferramentas em um contexto social para satisfazer os objetivos desejados.

A relação entre os sujeitos e o objeto é mediada pelo uso de ferramentas; o objeto representa a natureza objetiva da atividade humana que permite os indivíduos controlarem seus próprios motivos e comportamento ao realizar determinada atividade. As ferramentas refletem o aspecto mediacional da atividade humana: a ferramenta pode ser qualquer coisa usada pelo sujeito no processo de transformar o objeto em resultado (uma caneta, um computador ou mesmo a linguagem). As ferramentas alteram e são, por sua vez, alteradas pela atividade, uma vez que medeiam as relações entre sujeitos e objeto.

A comunidade situa a atividade em estudo dentro do contexto sociocultural daqueles sujeitos que compartilham o mesmo objeto. O relacionamento entre os sujeitos e a comunidade é mediado por regras, salientando o fato de que dentro de uma comunidade há regras, convenções e práticas de trabalho que afetam a maneira como a atividade está sendo desenvolvida. As regras podem ser explícitas (leis, normas) ou implícitas (costumes); as relações sociais dentro da comunidade (relações de amizade e poder) também estabelecem regras. A divisão de trabalho refere-se à distribuição de responsabilidades e à variação de papéis entre os sujeitos envolvidos na execução da atividade. Trata-se da organização 
implícita e explícita de uma comunidade. A divisão de trabalho medeia o relacionamento entre a comunidade e o objeto, buscando transformar esse objeto em resultado.

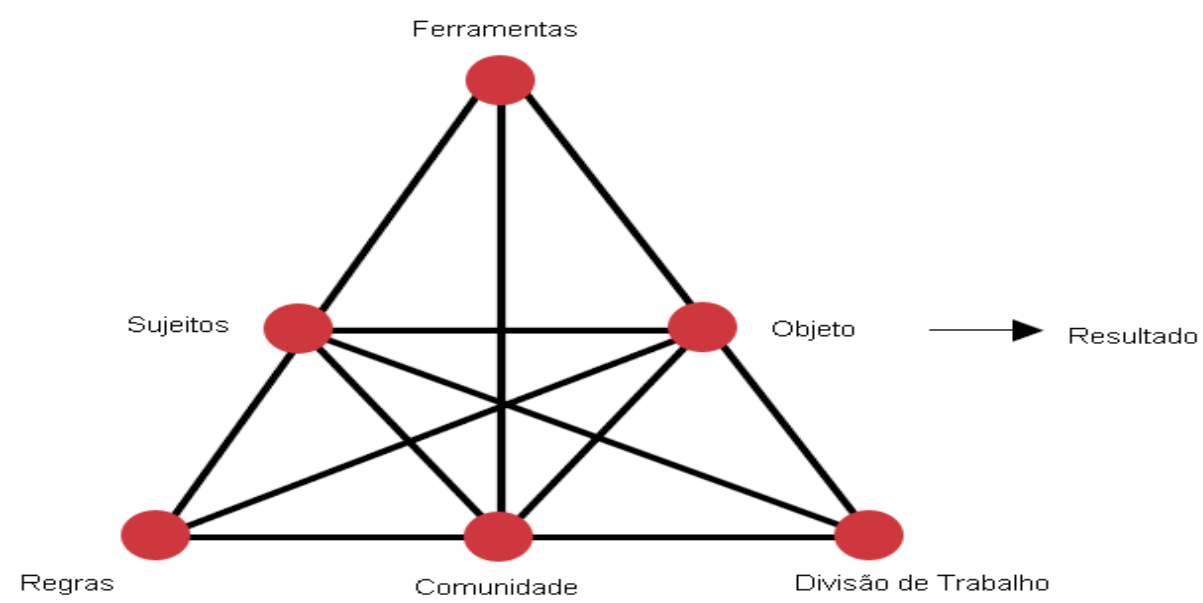

Figura 1 - Sistema de Atividade Humana (Engeström, 1987)

\section{AS CONTRADIÇÕES}

As contradições constituem um elemento chave na teoria da atividade (Engeström, 2001) e são características dos sistemas de atividade (Engeström, 1987; cf. Figura 2). Contradições não são o mesmo que problemas ou conflitos para Engeström (1987), ainda que alguns autores as classifiquem como tal (Dippe, 2006; Basharina, 2007). "As contradições são tensões estruturais acumuladas historicamente dentro e entre sistemas de atividade" (Engeström, 2001, p. 137) e geram perturbações e conflitos, mas também tentativas de inovação para mudar a atividade. Para Cole e Engeström (1993), nos sistemas de atividade, “o equilíbrio é uma exceção e as tensões, perturbações e inovações locais são a regra e o agente de mudança" (p. 8). 


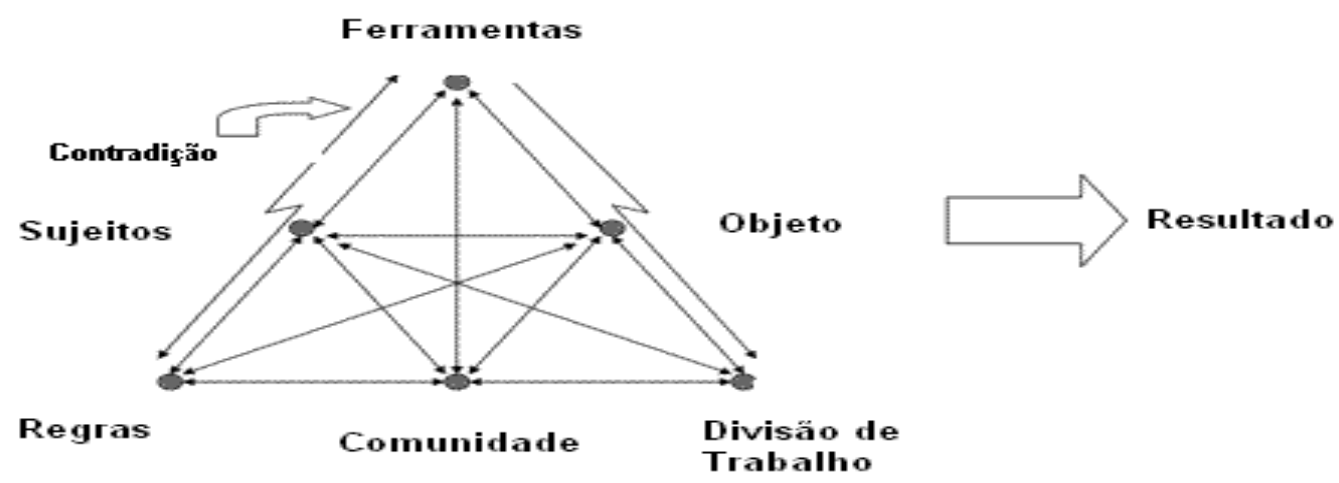

Figura 2 - As Contradições (adaptado de Engeström, 1987)

Embora o termo contradição possa remeter a uma concepção negativa, tal ideia serve como força motriz para mudanças e desenvolvimento em sistemas de atividade (Engeström, 1987, 1999, 2001). Tal ideia foi primeiramente apresentada por Ilyenkov (1977) e tornou-se um princípio diretriz nas pesquisas empíricas nos sistemas de atividade (Engeström, 2001). De acordo com a teoria da atividade, o desenvolvimento ocorre quando as contradições são superadas (Kuutti, 1996) e a principal fonte das contradições é, conforme Marx (1982), a divisão de trabalho existente na sociedade capitalista. Engeström (1992) inclusive sugere que o estudo das contradições manifestadas por meio de problemas e superadas por inovações proporciona uma visão mais significativa sobre os sistemas de atividade do que o estudo de interações estáveis. Dentro de um sistema de atividade, todos os elementos constantemente interagem uns com os outros e estão sempre sujeitos a funcionarem por meio de mudanças. Alterações em uma ferramenta podem modificar a orientação do sujeito em relação ao objeto, que, por sua vez, pode influenciar as práticas culturais da comunidade. Além disso, é possível que o próprio objeto e motivo também sofram mudanças durante o processo da atividade (Kuutti, 1996).

Apesar do potencial das contradições para resultar em transformações nos sistemas de atividade, essa transformação nem sempre ocorre. Na verdade, as contradições podem tanto propiciar uma aprendizagem para o desenvolvimento, como podem também restringir a aprendizagem, dependendo se elas são reconhecidas e resolvidas, ou não (Nelson, 2002). Da mesma forma, as soluções para as contradições não podem ocorrer no nível individual, uma vez que as contradições estão nas relações sociais entre grupos de pessoas e as ferramentas que elas usam (Wardle, 2004). 


\section{O SISTEMA DE ATIVIDADE EM ESTUDO: PORTUGUÊS REDACIONAL BÁSICO (PRB)}

O sistema de atividade em estudo refere-se a uma disciplina chamada de Português Redacional Básico (PRB) que faz parte de um grupo de disciplinas oferecidas a distância pela Universidade Católica de Pelotas (RS). A disciplina de PRB, com carga horária total de 68 h/a, é considerada obrigatória nos cursos de Direito, Ciências Contábeis, Administração, Arquitetura, Química, Jornalismo e Comunicação. Ela tem como objetivo a produção de textos dissertativos argumentativos com coesão e coerência, demonstrando o domínio dos aspectos gramaticais essenciais para a produção de textos acadêmicos de acordo com a norma padrão da língua e a capacidade argumentativa por meio da escrita. Os módulos de PRB foram oferecidos por meio de um software livre chamado TelEduc versão 3.8, que é um ambiente para a realização de cursos a distância via Internet e consiste em uma plataforma desenvolvida no NIED (Núcleo de Informática Aplicada a Educação/UNICAMP). Este ambiente de aprendizagem possui um sistema de acesso por meio de senha e identificação pessoal, solicitado quando o participante acessa o curso. Sua página inicial é dividida em duas partes: à esquerda, estão dispostos, em uma coluna, os espaços (ou ferramentas) e à direita, tem-se o conteúdo correspondente a determinado espaço (ou ferramenta), selecionado na coluna da esquerda.

Os procedimentos didáticos usados na disciplina de PRB foram: leituras de textos selecionados, incluindo coletâneas de pequenos textos para a explosão de ideias; produção de textos pelos alunos com disponibilização no portfólio para comentário (parecer) dos colegas e do professor; atividades interativas com feedback automático produzidos pelo sistema de autoria $\mathrm{ELO}^{1}$ e debates nos fóruns.

\footnotetext{
${ }^{1}$ Ensino de Línguas Online. Disponível em: http://www.leffa.pro.br/elo/
} 


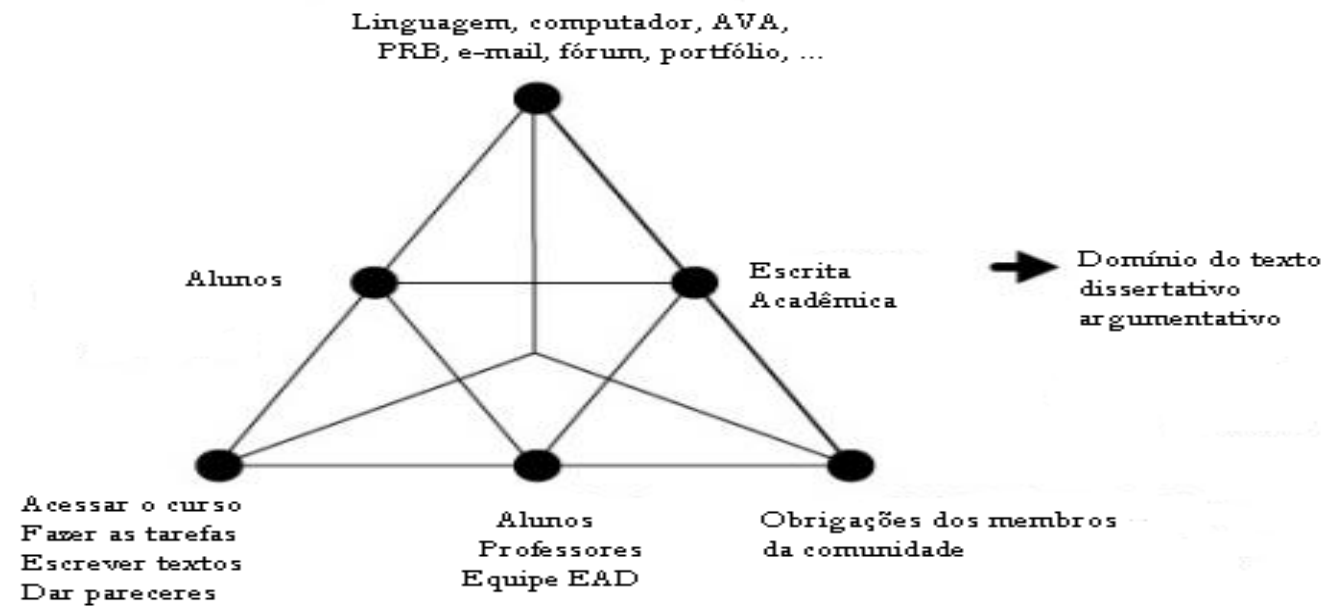

Figura 3 - Sistema de Atividade da Disciplina de PRB

Os sujeitos do sistema de atividade em questão (cf. Figura 3) eram 60 alunos, dentre os quais, oito não participaram efetivamente e três nunca acessaram, com idades que variam entre 18 e 49 anos de cursos diversos, já mencionados anteriormente. O objeto é a escrita acadêmica, cujo resultado seria o domínio do texto dissertativo argumentativo. As ferramentas para mediação eram a o computador, as aulas online, os e-mails enviados entre os participantes, a linguagem utilizada, os textos escritos, o ambiente virtual de aprendizagem (AVA), dentre outros.

A comunidade era composta pelos alunos da disciplina, dois professores de Letras e a equipe de suporte de EAD. As regras explícitas para a realização da disciplina consistiam em criar textos dissertativos e argumentativos conforme tema dado; emitir no mínimo dois pareceres sobre o texto do colega; ler teoria e fazer exercícios interativos (ELO); pesquisar na Internet sobre pontuação e cursos de redação, disponibilizar e argumentar sobre a sua escolha; refletir sobre a organização de um texto; e fazer outros exercícios gramaticais mais pontuais. 


\section{AS CONTRADIÇÕES NA DISCIPLINA DE PRB}

Levando em conta que para a teoria da atividade é impossível evitar as contradições entre a atividade individual e a coletiva (Dippe, 2006), o sucesso ou o fracasso de um sistema depende da habilidade em resolver tais contradições, bem como das transformações mútuas dos indivíduos e dos sistemas coletivos (Hedesting e Kaptelinin, 2003). Sob esse aspecto, muitas contradições foram observadas na disciplina de PRB.

Conforme definição de Engeström (1987), as contradições primárias ${ }^{2}$ referem-se ao conflito entre o valor de uso e o valor de troca de algum bem, no caso em estudo, da disciplina PRB. O aluno pode fazer um curso (ou uma disciplina) pelo conhecimento que pode ser adquirido por meio dele (valor de uso) ou simplesmente pelo interesse em receber um certificado e obter promoção profissional (valor de troca). Nos trechos a seguir ${ }^{3}$, Bia reconhece o valor de uso da disciplina de PRB que é indispensável para qualquer profissão. Já Márcio salienta o seu interesse em "aderir a cargos importantes", enfatizando o valor de troca da disciplina. Ainda, na preocupação de Josie, o conhecimento (ou falta dele), não é o mais importante (valor de uso), mas o valor gasto (valor de troca) para cursar a disciplina.

Achei ótimo o curso! Facilita para quem trabalha e não dispõe de muito tempo livre. Além de, como principal qualidade, nos proporcionar um aprofundado estudo da língua portuguesa, que é indispensável para quaisquer profissões. (Bia)

Ingressei no curso de direito com a expectativa abrir grandes fontes de trabalho, por ser um dos que mais abre, no entanto gosto muito do curso e tenho vontade de aderir a cargos importantes, como promotor ou cargos parecidos. Acho que essa aula a distância vai ser bem legal pelo fato de ser diferente. (Márcio)

Porque eu não passei? Não estou acreditando... O senhor vai me deixar em exame por 0,03 ? Trabalho todo dia, estou pendurada em duas matérias e eu vou rodar em Português, sendo que é a matéria mais cara que faço? Por favor, o que aconteceu? Eu fiz quase todas as atividades. Se necessário vou até o Senhor para conversarmos, mas acredito ter alguma coisa errada. (Josie)

No trecho a seguir há uma contradição entre o sujeito e o objetivo da disciplina que é desenvolver a escrita acadêmica, não aceitando internetês. Carlos, em tom de brincadeira, escreve no Fórum; porém, ele defende o uso de internetês, uma vez que outros alunos já

\footnotetext{
${ }^{2} \mathrm{Na}$ concepção de Engeström (1987), as contradições ocorrem em quatro níveis: contradições primárias, secundárias, terciárias e quaternárias.

${ }^{3}$ Cumpre registrar que as questões éticas de privacidade foram observadas, garantindo aos participantes a utilização de pseudônimos em lugar de seus nomes verdadeiros e a autorização para uso dos dados por meio de consentimento informado.
} 
tinham escrito dessa forma. Tal contradição representa o conflito de objetivos que os alunos trazem; seus objetivos pessoais (apenas cumprir os créditos obrigatórios) são diferentes do objetivo do sistema de atividade da disciplina de PRB.

Não sei se estou atrasado neste fórum,mas achei o tema interessante.Não quero aqui defender o academicismo clássico da escrita,mas acho que o "internetês" coloca todos em um mesmo nível, principalmente jovens que já tem tanta dificuldade com a gramática.Criase um código e pronto: todo mundo tá na mesma sintonia e ninguém escreve melhor que ninguém...entaum ñ vamu skentah q eh o cinau dus tmpus. (Carlos)

Nos exemplos apresentados, a contradição está no objeto que é o que dá sentido e significado à atividade, determinando os valores de diversos outros fenômenos (Kaptelinin e Nardi, 2006). O objeto do sistema de atividade da disciplina de PRB é a escrita acadêmica que seria usada em outros documentos ao longo de diferentes cursos. Mas os alunos trazem consigo objetivos diferentes para a disciplina. É difícil ensinar a produção de textos para diferentes sujeitos com histórias e habilidades distintas e com motivos e necessidades que diferem entre si.

Outra contradição muito presente nos cursos à distância são os problemas com a tecnologia, que seria a contradição do sujeito e a ferramenta mediadora. Os exemplos a seguir mostram as dificuldades encontradas pelos alunos em relação à Internet, ao modem que estragou e ao sistema universitário (sapu).

To com o texto sobre esmola pronto, porém não estou conseguindo passá-lo para o portfólio porque a internet ta fora do ar. Sem mais para o momento, se possível agradeço pela compreensão. (Fernando)

Obrigado pela sua atenção!Se o senhor notar fiz a segunda atividade nos últimos dois dias, é que estava com problemas na internet, mas isso não se repetirá! Obrigado! (Carol)

Não consegui entregar todas as atividades no prazo devido ao meu modem ter queimado, agora já está tudo ok! Eu posso fazer as atividades ainda sem problema? Se sim.. até quando? (Bob)

Caro professor não tenho conseguido acessar o sapu, dá sempre fora do ar, e na atividade de pontuação eu tinha realizado e enviado o relatório, consta como não realizada no seu portfólio. (Márcia)

A conveniência de poder fazer uma disciplina online traz consigo a premissa de que o aluno necessita ter acesso a um computador conectado à Internet. Os alunos ficam frustrados quando não conseguem realizar com êxito suas tarefas, acarretando uma experiência negativa ao ensino à distância. A propagada conveniência da educação à distância entra em choque com os problemas tecnológicos. No entanto, questões tecnológicas são inerentes ao ensino à distância e é preciso saber lidar com tais dificuldades. 
Ainda, antes da disciplina de PRB, muitos dos alunos usavam o computador apenas para a leitura de e-mails ou para diversão. Trabalhar com o computador em um ambiente virtual de aprendizagem trouxe conflitos para esses alunos.

Mudou praticamente tudo, mas para melhor, pois, há muito tempo eu tinha computador em casa, e nunca tive motivação nenhuma, agora fui obrigada a me adaptar, e estou realmente gostando. (Malu)

(...) antes utilizava o computador apenas por diversão e contatos, agora tenho algo realmente útil para fazer! Mudou para melhor. (Paulo)

As contradições quaternárias ocorrem entre a atividade central e as atividades circunvizinhas a ela relacionadas. Foi comum ouvir dos alunos que não puderam cumprir com as atividades em função do trabalho. Os trechos a seguir demonstram a sua frustração por não conseguirem uma dedicação maior à disciplina. Cristian, com muita dificuldade na redação, reconhece que precisa se dedicar mais. Jane, Jim e Laura gostariam de ter participado mais, mas em função do trabalho, não conseguiram.

Tenho que me dedica mais a portugues redacional fazendo todos os trbalhos que me mando fazer,desdeque eu trabalho e chego muito cansado em casa e tanbem por nao ter computador e por fazer os trabalho so quando me da tempo sempre no final de semana e tambem nas lan house.(Cristian)

Minha participação na disciplina não foi tão intensa quanto eu gostaria que fosse. Infelizmente minha atividade profissional tomou grande parte do meu tempo, impossibilitando outras atividades. Apesar de tudo, na grande maioria das vezes o tempo que me sobrou foi de dedicação total as atividades do PRB. (Jane)

Peço desculpas por nessa reta final, não ter conciliado o trabalho, com o curso. Mas gostaria de registrar que foi de total importância para o meu conhecimento esse curso. (Jim)

Meu desempenho poderia ter sido melhor mas em função de meu trabalho fica complicado. (Laura)

A grande maioria dos alunos optou pela disciplina de PRB à distância ${ }^{4}$ devido à falta de tempo para estudar na modalidade presencial; porém, é justamente desse tempo, que eles não dispõem que precisam para estudar a distância. O sistema de atividade profissional exerce influências no aluno fazendo com que ele rompa, muitas vezes, a sua rotina de estudo ou até mesmo com obrigações assumidas. O aluno trabalhador envolve-se em uma rotina desgastante e não consegue tempo para estudar.

\footnotetext{
${ }^{4}$ A disciplina de PRB também foi oferecida na modalidade presencial.
} 


\section{AS COMUNIDADES VIRTUAIS DE APRENDIZAGEM}

Na visão de Lave e Wenger (1991), a aprendizagem envolve a participação em uma comunidade de prática. As comunidades de prática são uma das formais sociais que estruturam a colaboração no local de trabalho. O termo comunidade de prática surgiu no trabalho de Lave e Wenger (1991) e foi ampliado por Wenger (1998). As comunidades de prática, também chamadas de comunidades de aprendizagem ou comunidades virtuais, são definidas como "um conjunto de relações entre pessoas, atividades, e o mundo, ao longo do tempo e em relação com outras comunidades de prática tangenciais e sobrepostas que têm algo em comum" (Lave e Wenger, 1991, p.98). Wenger (1998) enfatizou as comunidades de prática como um lugar para aprendizagem em organizações. Ele observou que a aprendizagem é situada e ocorre em práticas progressivas. Wenger também notou que relacionamentos e interações constantes nos locais de trabalho reforçam uma comunidade de prática. Os trabalhadores aprendem a prática da sua profissão através da participação direta em uma comunidade de prática (Nardi et al., 2000).

Uma vez que as comunidades de prática podem ser vistas como a manifestação de fatores situacionais constituintes de uma prática social, a teoria da atividade ajuda a identificar e entender estes fatores (Leontiev, 1981). A teoria da atividade sustenta que as ações humanas são o produto das ações sociais que são historicamente e culturalmente constituídas; assim, os fatores situacionais moldam as ações humanas (Engeström, 1996). A teoria da atividade embasa o entendimento de como as atividades nas quais os indivíduos estão engajados moldam sua forma de pensar e de agir. Para entender a aprendizagem a partir dessa perspectiva, deve-se considerar que as atividades direcionadas a um objetivo têm consequências cognitivas de reforçar ou refinar o que os indivíduos já sabem, ou de gerar novo conhecimento se a atividade é nova (Billett, 2002). Assim, as atividades estruturam a cognição (Rogoff e Lave, 1984). Ainda, as interações entre as fontes sociais (os outros, os artefatos, os símbolos) são vistas por Vygotsky (1978) como fonte de cognição.

A teoria da atividade vê os processos motivacionais e cognitivos inseridos dentro de estruturas de atividades maiores. As estruturas das atividades envolvem mediadores ferramentas e símbolos - que têm profundas implicações na maneira como as tarefas intelectuais são desempenhadas (Martin e Scribner, 1991, p.583). Os elementos do sistema social contribuem coletivamente para o conhecimento e para a aprendizagem, com o indivíduo sendo visto como um elemento neste sistema. Outros elementos incluem atividades direcionadas, relações interpessoais e ferramentas. Mais do que simplesmente um mero 
contexto no qual o pensamento e a performance ocorrem, as situações moldam as atividades, os seus objetivos e as atividades cognitivas dos pensamentos, das ações e da aprendizagem dos indivíduos (Hutchins, 1991). O que mantém unida uma comunidade de prática é um senso comum de intenção e uma real necessidade de conhecer o que cada um sabe. Wenger (1998) descreve três dimensões importantes das comunidades de prática:

(1) domínio: as pessoas se organizam ao redor do domínio do conhecimento que dá aos membros uma sensação de terem um empreendimento em comum e faz com que eles fiquem juntos;

(2) comunidade: as pessoas funcionam como uma comunidade de engajamento mútuo que as mantêm juntas como uma entidade social. Elas interagem regularmente e se engajam em situações mútuas, construindo relacionamento e confiança;

(3) prática: a habilidade é construída na prática por recursos compartilhados - ferramentas, documentos, rotinas, vocabulário, símbolos - que incorporam o conhecimento acumulado da comunidade. Esses recursos compartilhados servem para futuras aprendizagens.

As comunidades requerem uma sensação de missão: há alguma questão que as pessoas querem realizar juntas e surge a partir de seus entendimentos compartilhados. Quando as pessoas estão engajadas em tarefas similares, a necessidade de compartilhar o que elas sabem irá guiá-las à formação de uma comunidade. Uma rede de conhecimento de pessoas com interesses comuns pode formar uma comunidade uma vez que as pessoas reconheçam oportunidades a serem compartilhadas.

\section{AS FERRAMENTAS E OS ESPAÇOS DE APRENDIZAGEM}

Palloff e Pratt (2002) salientam que a ferramenta utilizada em um curso à distância deve ser funcional (fácil para enviar o material do curso e criar fóruns de discussão), de simples operação para professor/aluno e amigável, visualmente atraente e de fácil navegação. As ferramentas e os espaços devem ajudar a promover interação entre os participantes. Ao invés de falarmos em ferramentas, seguiremos a orientação de Peters (2003) e daremos diferentes designações para os espaços virtuais de aprendizagem. O real para o aluno é o ambiente informatizado de aprendizagem com a tela do monitor como interface. Espaços virtuais são criados quando o "vazio imaginado por trás da tela é transformado em um palco imaginado para atividades" (Peters, 2003, p.166).

O espaço de instrução corresponde à página de entrada do curso, com informações ou sugestões dos professores para os alunos e serve como um canal de comunicação direta com o aluno; nesta página estão dispostas as atividades que os alunos devem fazer em um 
dado período de tempo (agenda). No curso, a agenda era trocada a cada duas ou três semanas. O espaço de informação refere-se ao mural que contém informações importantes a respeito de notícias. O mural foi utilizado para divulgar os resultados parciais do andamento das unidades por parte dos alunos. A publicação dos resultados também era uma maneira do professor negociar comunicação com o aluno; pois, caso a divulgação não estivesse correta, os alunos se viam obrigados a contatar o professor, nem que fosse somente para reclamar. $\mathrm{O}$ espaço de comunicação é o correio, um serviço de e-mail dentro do ambiente TelEduc, que também pode mandar uma cópia para o e-mail particular do aluno, e a lista de discussão criada com o Google groups. O espaço de colaboração e reflexão refere-se ao fórum de discussão. Nesse espaço, os alunos participavam conforme as propostas das agendas. O espaço de documentação é o portfólio que armazena textos e arquivos desenvolvidos durante o curso com dados que podem ser compartilhados com professores e colegas, e permite que comentários sejam inseridos. No portfólio, os alunos armazenavam os textos escritos que ficavam à disposição para serem avaliados pelos professores e colegas (atividade obrigatória de emitir pareceres).

Esses foram os espaços/ferramentas utilizados com o intuito de promover a interação entre alunos, professores e conteúdo na tentativa de formar uma comunidade de aprendizagem online.

\section{CONSIDERAÇÕES FINAIS}

O sistema de gêneros é também parte do sistema de atividades da sala de aula. Ao definir o sistema de gêneros que as pessoas estão envolvidas, identificamos também o que organiza o seu trabalho, sua atenção e suas realizações, voltando-nos à questão de ensinar como argumentar em um texto, por exemplo, para diferentes cursos. Em algumas situações os gêneros orais são predominantes, mas quando há o deslocamento para cima na escala educacional e entrada no mundo profissional, o sistema de gêneros escritos se torna especialmente importante.

Levar em consideração o sistema de atividade junto com o sistema de gêneros é focalizar o que as pessoas fazem e como os textos ajudam as pessoas a fazê-lo, em vez de focalizar os textos como fins em si mesmo.

Assim, vários tipos de textos agrupam-se em conjuntos de gêneros dentro de sistemas de gêneros que fazem parte dos sistemas de atividade humana. Por isso devemos voltar nossa atenção ao estudo dos gêneros textuais, pois compreender os gêneros e o seu funcionamento 
dentro dos sistemas e nas circunstâncias para as quais foram criados pode ajudar o aluno a compreendê-los e fazer com que corresponda às expectativas dos outros. Desta forma, compreender os gêneros também auxilia a perceber quando textos aparentemente bem produzidos não atingem sua função comunicativa e, também, a saber diagnosticar e redefinilos para que cumpram sua função. Conhecendo os gêneros textuais que os alunos utilizam na sua prática diária (ou pelo menos deveriam utilizar), na sua atividade, ou na área na qual estão buscando formação, temos mais condições de trabalhar com textos realmente significativos para eles, que sejam fatos sociais que levem à ação, já que é por meio da ação que ocorre a aprendizagem.

\section{REFERÊNCIAS}

Basharina, O. K. (2007).An activity theory perspective on student-reported contradictions in international telecollaboration. Language Learning \& Technology,11, (2), 82-103.

Bakhtin, M. (1997). Os Gêneros do Discurso. In: Estética da Criação Verbal. São Paulo: Martins Fontes.

Barboza, J. P. (2001). Trabalhando com os gêneros do discurso: uma perspectiva enunciativa para o ensino de língua portuguesa. Tese de Doutorado, PUC - São Paulo.

Bazerman, C. (2005). Gêneros textuais, tipificação e interação. São Paulo: Cortez.

Gêneros, Agência e Escrita. (2006). Judith C. Hoffnagel; Ângela P. Dionísio (orgs). São Paulo: Cortez.

Billett, S. (2002). Workplaces communities, and pedagogy. In: Lea, M.; Nicoll, K.Distributed Learning Social and Cultural Approaches to Practice 83-97. Londres: Falmer Press.

Bodker, S. (1991).Activity theory as a challenge to system design. In: Nissen, H.E. et al. Information system research: Contemporary approaches and emergent traditions. Amsterdam, Elsevier.

Brait, B. (2002). Língua e Linguagem.São Paulo: Ática.

Cole, M.\&Engeström, Y. (1993). A cultural-historical approach to distributed cognition. In: Salomon, G. (Ed.). Distributed cognitions, psychological and educational considerations 146.Cambridge: Cambridge University Press.

Daniels, H. (2008). Vygotsky and Research. London: Routledge.

Dippe, G. (2006). The missing teacher: Contradictions and conflicts in the experience of online learners. Proceedings of the Fifth International Conference on Networked Learning 2006.Lancaster: Lancaster University. Disponível em: 
http://www.networkedlearningconference.org.uk/past/nlc2006/abstracts/pdfs/P38\%20Dippe.P DF. Acesso em dezembro 2010.

Engeström, Y. (1987). Learning by Expanding: An Activity- Theoretical Approach to Development Research.Helsinki: Orienta-Konsultit Oy, Finland. Disponível em:http://lchc.ucsd.edu/mca/Paper/Engestrom/expanding/toc.htm. Acesso em julho 2010.

(1992). Interactive Expertise: Studies in Distributed Working Intelligence. Research Bulletin 83, 1992.

(1996). Developmental studies of work as a testbench of activity theory: the case of primary care medical practice. In: Chaiklin, S. \& Lave, J. (ed) Understanding Practice: Perspectives on Activity and Context64-103. Cambridge: Cambridge University Press.

(1999). Innovate learning in work teams: analyzing cycles of knowledge creation in pratice. In: Engeström,Y; Miettinen, R. \& Punamaki, R. L. Perspectives on Activity Theory377-404. Cambridge: Cambridge University Press.

- (2001). Expansive learning at work: towards and activity theoretical reconceptualization. Journal of Education and Work, 14 (1), 133-156.

Hedesting, U. \&Kaptelinin, V. (2003). Facilitator's Invisible Expertise and Supra-Situational Activities in a Telelearning Environment. Proceedings of the 36 the Annual Hawaii International Conference on System Sciences.

Hutchins, E. (1991).The social organization of distributed cognition. In: Resnick, L.B. et al. Perspectives on Socially Shared Cognition15-34. Washington, DC: American Psychological Association.

Ilyenkov, E. (1977).Dialectical logic: Essays on its history and theory. Moscow: Progress.

Kaptelinin, V. \& Nardi, B.A. (2006). Acting with technology:activity theory and interaction design.Cambridge, MA: MIT Press.

Kuutti, K. (1996). Activity Theory as a Potential Framework for Human-Computer Interaction Research. In: Nardi, B. A. (ed) Context and Consciousness: Activity theory and human-computer interaction17-44. Cambridge, Mars: MIT Press.

Lave, J. \& Wenger, E. (1991). Situated Learning: Legitimate Peripheral Participation. Cambridge: Cambridge, University Press.

Leontiev, A.N. (1981). The problem in Activity in Psychology. In: Wertsch, J.V. The Concept of Activity in Soviet Psychology: An Introduction37-71...M.E. Sharpe, Inc. New York: USA.

Marcuschi, L.A. (2002). Gêneros textuais: definição e funcionalidade. In: Dionisio, Â. et al. Gêneros textuais e ensino19-36. Rio de Janeiro: Lucerna.

Apresentação. (2005). In: Bazerman, C. Gêneros textuais, tipificação e interação0913. Trad. e org. de A. P. Dionísio e J. C. Hoffnagel. São Paulo: Cortez. 
Martin, L.M. \& Scribner, S. (1991). Laboratory for cognitive studies of work: a case study of the intellectual implications of a new technology. Teacher College Record, 92 (4), 582-602.

Marx, K.(1982).O Capital. $7^{\text {a }}$ ed. Rio de Janeiro: LTC.

Miller, C. Genre as Social Action. (1994). In: Freedman, A. \&Medway, P. (eds). Genre and the New Rethoric23-42. London: Taylor and Francis, London, UK.

Nardi, B. A. (1996). Studying Context: a comparison of activity theory, situated action models, and distributed cognition. In: Nardi, B. A. (ed) Context and Consciousness: Activity Theory and Human-Computer Interaction 69-102. Cambridge, MA: The MIT Press.

Nardi, B. et al. (2000). It's Not What You Know, It's Who You Know: Work in the Information Age. First Monday, 5 (5). Disponível em http://firstmonday.org/htbin/cgiwrap/bin/ojs/index.php/fm/issue/view/119. Acesso em dezembro 2010.

Nelson, C. (2002). Contradictions in learning to write in a second language classroom: Insights from radical constructivism, activity theory, and complexity theory. Tese de Doutorado. The University of Texas at Austin.

Peters, Otto. (2003). A Educação a Distância em Transição. São Leopoldo: UNISINOS.

Palloff, R. M. \& Pratt, K. (2002). Construindo Comunidades de Aprendizagem no Ciberespaço. Porto Alegre: Artmed.

Ribeiro, M. O. (2001). Ensinar ou não ensinar a gramática na sala de aula, eis a questão. Linguagem e Ensino, 4 (1) 141-157. Pelotas: Educat.

Rojo, R. (2000). A prática de linguagem em sala de aula: praticando os PCNs. São Paulo: Mercado de Letras.

Rojo, R. \& Cordeiro, G. S. (2004). Apresentação: gêneros orais e escritos como objetos de ensino: modos de pensar, modos de fazer. In: B. Schneuwly \& J. Dolz (eds.) Gêneros Orais e

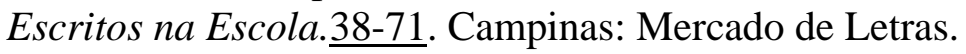

Russell, D. (1995). Activity Theory and Its Implications for Writing Instruction. In:Petraglia, J. (ed). Reconceiving Writing, Rethinking Writing Instruction 51-78. Hillsdale, NJ: Erlbaum.

Rogoff, B. \& Lave, J. (1984). Everyday Cognition: Its Development in Social Context.Cambridge, MA: Harvard University Press.

Schneuwly, B. (2004). Gêneros e tipos de discurso: considerações psicológicas e ontogenéticas. In: B. Schneuwly\&J. DolzGêneros Orais e Escritos na Escola21-40. Campinas: Mercado de Letras. 
Signorini, I. (2006). Gêneros catalizadores: letramento e formação do professor. São Paulo: Parábola.

Vygotsky, L. (1978).Pensamento e linguagem. São Paulo: Martins Fontes.

Wardle, E. A. (2004). Can cross-disciplinary links help us teach "academic discourse" in FYC? Across the Disciplines, 1. Disponível em http://wac.colostate.edu/atd/articles/wardle2004/. Acesso em setembro 2010.

Wenger, E. (198). Communities of Practice: Learning, Meaning and Identity. Cambridge: Cambridge University Press.

\begin{abstract}
A AUTORA
Christiane Heemann é Mestre em Linguística Aplicada e Doutora em Letras pela Universidade Católica de Pelotas (RS), com doutorado sanduíche (CAPES) na University of Bath (UK). Interesse de pesquisa: ensino à distância, comunidades virtuais de aprendizagem; ensino de línguas online.
\end{abstract}

E-mail: chrisheemann@gmail.com 